\title{
Identification of estrogen receptor proteins in breast cancer cells using matrix-assisted laser desorption/ionization time of flight mass spectrometry (Review)
}

\author{
ZBYNEK HEGER $^{1,2}$, MIGUEL ANGEL MERLOS RODRIGO ${ }^{1}$, SONA KRIZKOVA $^{2,3}$, \\ ONDREJ ZITKA ${ }^{1-3}$, MIROSLAVA BEKLOVA ${ }^{2}$, RENE KIZEK ${ }^{2,3}$ and VOJTECH ADAM ${ }^{2,3}$ \\ ${ }^{1}$ Department of Veterinary Ecology and Environmental Protection, Faculty of Veterinary Hygiene and Ecology, \\ University of Veterinary and Pharmaceutical Sciences Brno, Brno CZ-612 42; ${ }^{2}$ Department of Chemistry and Biochemistry, \\ Faculty of Agronomy, Mendel University in Brno, Brno CZ-613 00; ${ }^{3}$ Central European Institute of \\ Technology, Brno University of Technology, Brno CZ-616 00, Czech Republic
}

Received June 29, 2013; Accepted December 6, 2013

DOI: $10.3892 / \mathrm{ol} .2014 .1912$

\begin{abstract}
Estrogen receptors [ERs (subtypes $\alpha$ and $\beta$ )], classified as a nuclear receptor super family, are intracellular proteins with an important biological role as the transcription factors for estrogen target genes. For ER-induced transcription, an interaction must exist between ligand and coregulators. Coregulators may stimulate (coactivators) or inhibit (corepressors) transcription, following binding with a specific region of the gene, called the estrogen response element. Misbalanced activity of coregulators or higher ligand concentrations may cause increased cell proliferation, resulting in specific types of cancer. These are exhibited as overexpression of ER proteins. Breast cancer currently ranks first in the incidence and second in the mortality of cancer in females worldwide. In addition, $70 \%$ of breast tumors are $\mathrm{ER} \alpha$ positive and the importance of these proteins for diagnostic use is indisputable. Early diagnosis of the tumor and its classification has a large influence on the selection of appropriate therapy, as ER-positive tumors demonstrate a positive response to hormonal therapy. Matrix-assisted laser desorption/ionization time of flight mass spectrometry (MALDI TOF MS) has been hypothesized to have great potential, as it offers reliable, robust and efficient analysis methods for biomarker monitoring and identification.
\end{abstract}

Correspondence to: Professor Vojtech Adam, Department of Chemistry and Biochemistry, Mendel University in Brno, Zemedelska 1, Brno CZ-613 00, Czech Republic

E-mail:vojtech.adam@mendelu.cz

Abbreviations: ER, estrogen receptor; $\mathrm{ER}^{+}$, estrogen receptor positive; $\mathrm{PgR}^{+}$, progesteron receptor positive; $\mathrm{ERE}$, estrogen response element; MALDI TOF, matrix-assisted laser desorption/ionization time of flight

Key words: matrix-assisted laser desorption/ionization time of flight, estrogen receptor, estrogen response element, cancer
The present review discusses ER protein analysis by MALDI TOF MS, including the crucial step of protein separation.

\section{Contents}

1. Introduction

2. Estrogen receptor (ER) proteins and tumor diseases

3. Matrix-assisted laser desorption/ionization time of flight (MALDI TOF) as a tool for analysis of ERs

4. Immunohistochemistry versus MALDI TOF

5. Conclusions

\section{Introduction}

In 2011, breast cancer ranked first in the incidence and mortality of tumor diseases (1). Currently, it is the leading cause of cancer and continues to be the second most common cause of cancer mortality in females worldwide (2). In developed countries, the lower mortality rate is attributed to mammographic screening and advances in adjuvant therapy (3). The most commonly diagnosed breast cancer subtypes are luminal A and $\mathrm{B}$ tumors $(4,5)$, together defined as the ER-positive $\left(\mathrm{ER}^{+}\right)$ and progesterone receptor-positive $\left(\mathrm{PgR}^{+}\right)$tumors (6-8). In total, $>70 \%$ of breast cancers are $\operatorname{ER}^{+}(9,10)$ and, thus, ERs remain the most informative biomarkers in specific subtypes of breast tumors $(3,11)$. The ERs (subtypes $\alpha$ and $\beta$ ) are members of the nuclear receptor family of proteins modulating the expression of genes in response to ligand binding (12-14). ER $\alpha$ expression occurs in bones, the uterus, mammary gland, liver and adipose tissue, whereas ER $\beta$ is predominantly expressed in the ovary, mammary gland and intestinal tract. There is also expression of the two subtypes in the brain and cardiovascular system (15). ERs are located in the cell cytoplasm in a complex with the heat shock protein 90 chaperone, which dissociates following ligand binding (16). The ER-ligand complex is translocated into the nucleus, where it interacts with coregulators of transcription and binds to the estrogen response element (ERE) promoter 


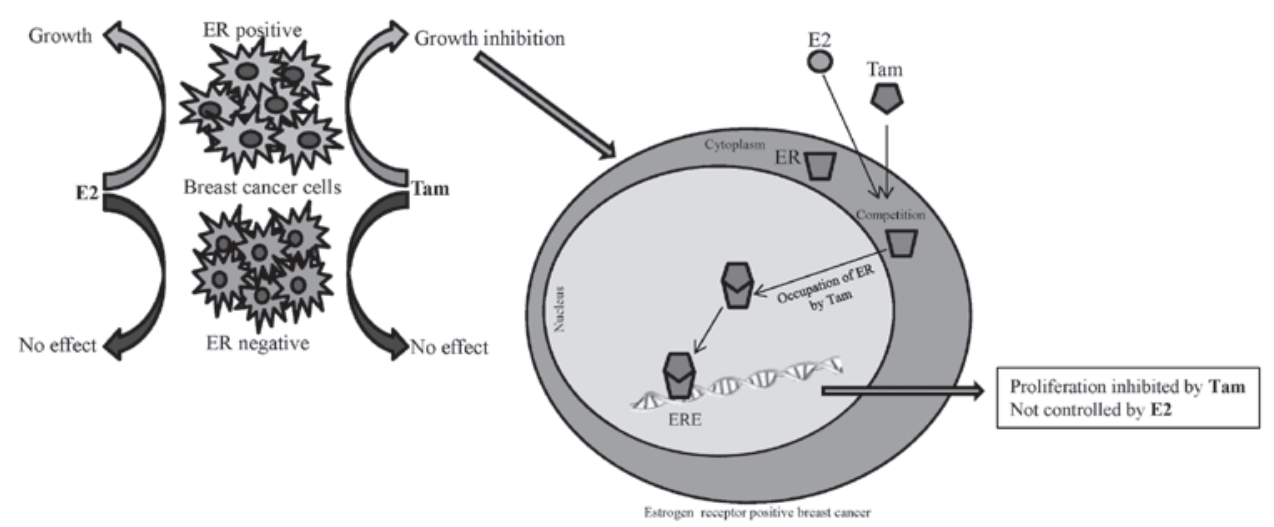

Figure 1. Schematic representation of hormone treatment action in ER-positive breast cancer cells. E2, estradiol; Tam, tamoxifen; ER, estrogen receptor; ERE, estrogen response element.

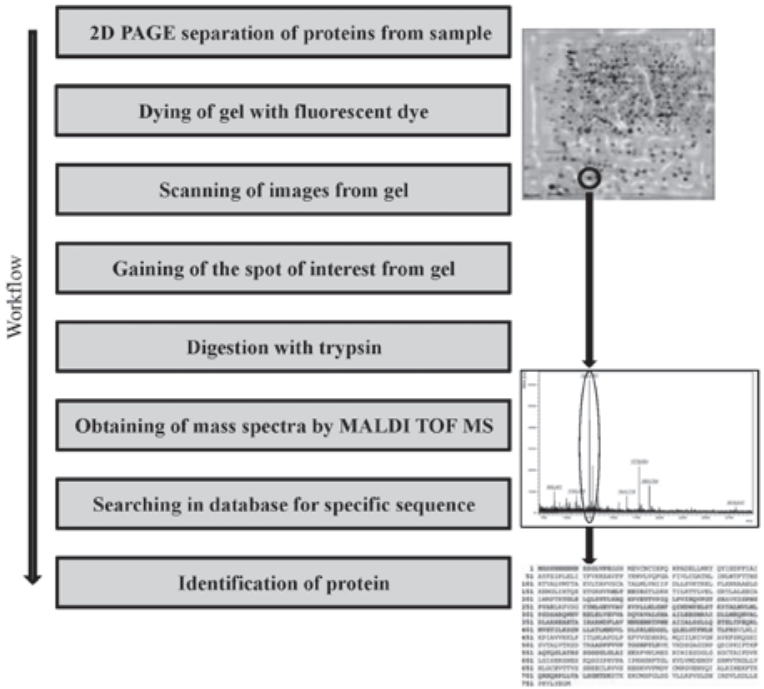

Figure 2. Schematic representation of protein identification in cancer cells by MALDI TOF MS. MALDI TOF MS, matrix-assisted laser desorption/ionization time of flight mass spectrometry.

region of a target gene and thereby activates mRNA transcription (17-19). Identification of biomarkers using matrix-assisted laser desorption/ionization (MALDI) is currently of increasing significance and has contributed to rapid advances in metabolomics (20). MALDI may also be a powerful tool for investigation of biomarkers in biological systems, through the direct analysis of thin tissue sections (21), for example ERs in breast tissue. The present review aimed to summarize the evidence for the use of MALDI time of flight mass spectrometry (TOF MS) for the identification of ER proteins in breast cancer tissues.

\section{ER proteins and tumor diseases}

ERs and cancer. Molecules acting as ER agonists generally exert a stimulatory effect on the proliferation of estrogen-sensitive breast carcinoma cells (12). In human breast cancer, $\mathrm{ER}^{+}$tumors exhibit an overexpression of ER $\alpha$ as a result of transcription from a promoter inactive in normal breast epithelium. In addition, behavior of ER $\alpha$ depends on the structure of the bound ligand [e.g. estradiol, the most active estrogen (22)] modulating the transcriptional activity of the estrogen responsive genes $(18,23) . \mathrm{ER} \alpha$, as a main target in breast cancer, is influenced by a number of types of coregulator following ligand binding, including coactivators and corepressors (24). The balance between coregulators is crucial for regulation of gene transcription by $\mathrm{ER} \alpha$ (25). Overexpression of coactivators, for example coactivator-associated arginine methyltransferase 1, may also increase the expression of ER $\alpha$ target genes involved in breast tumor cell differentiation and proliferation (26), including breast cancer (BRCA) 1 and BRCA2 genes (27). In addition, reduction of ER $\alpha$ spliced variant 46 (46 kDa) and $36(36 \mathrm{kDa})$ mRNA levels have been observed in colon tumors (28) and overexpression of ER $\alpha 36$ has been observed in gastric (29) and endometrial cancers (30).

Role of ERs in diagnostics. It is well known that ER levels and emplacement of breast tumor metastasis are the fundamental and critical determinants of clinical outcome, with high prognostic values having the greatest impact on patient survival chances $(31,32)$. The importance of ERs as breast carcinoma biomarkers is also due to the ability of the hormone receptor protein to provide detailed information about breast tumor subtype. $\mathrm{ER}^{+}$breast cancer types exhibit favorable responses to hormone therapy (33-35), for example tamoxifen (36), or to aromatase inhibitors (37), designed to block aberrant signaling within oncogenic pathways (Fig. 1). The use of neoadjuvant chemotherapy for the treatment of $\mathrm{ER}^{+}$tumors is associated with a major obstacle; chemoresistance $(38,39)$. Hence, the identification of cancer subtypes using protein analysis is likely to enable the treatment effects of chemotherapy to be maximized (40). At present, the most utilized method for ER protein analysis in practice is immunohistochemistry (41-45). Great potential has also been attributed to MALDI TOF MS offering reliable, robust and efficient analysis, renowned for its ease of operation and inexpensive matrixes required for sample preparation, as well as its derivative, surface-enhanced laser desorption/ionization spectrometry (20).

\section{MALDI TOF as a tool for analysis of ERs}

MALDI TOF has been hypothesized to represent one of the most comprehensive and versatile tools for investigation of 
new biomarkers and protein analysis (46). A key element of the proteomic application of MALDI TOF is the separation of proteins from a sample using two-dimensional gel electrophoresis, prior to subsequent analysis by MS (Fig. 2) (47,48). The MALDI TOF result, exhibited as protein peak spectra, may be quantitatively and statistically evaluated for determination of differential protein expression in response to a particular biological state (49). Nalvarte et al reported an approach for the isolation of $\mathrm{ER} \alpha$ from MCF-7 cells based on the natural affinity of ER proteins towards the estrogen response element immobilized on a Sepharose column with subsequent two-dimensional electrophoresis, and identification using MALDI TOF mass spectrometry (50). This method provided a rapid method to identify ER $\alpha$ cofactor and transcription factor recruitment under various conditions. However, it has been hypothesized that the equivalent analysis of ER proteins in clinical samples is likely to be subject to extensive chemical noise that may invalidate results (51). The quantity and identity of biomarkers observed in tissue profiles are also influenced by a number of factors, including the volume of matrix solution used and the sites of laser shots application, used for ionization, which provides charge to molecules and thus enables proper mass detection, which facilitates rendering of the data into spatial distribution maps, or images for the many hundreds of ions measured in the mass spectra (52). A potential problem may be found also in the variability in sample preparation, leading to crystal heterogeneity, and thus to discrimination and suppression of certain signals. There are various approaches to minimize MALDI analysis, including the production of thin films by rapid drying of volatile solvents, or the use of electrospray with the ability to produce thin homogeneous films (51). The lack of further evidence associated with the diagnosis of breast cancer by MALDI TOF analysis of ERs highlights the issues associated with ER protein analysis in real biological samples. However, this method demonstrates excellent results for the visualization of protein expression (46,53), DNA methylation status (54), monitoring of ER interactions $(55,56)$ and in searching for new biomarkers for breast cancer diagnosis $(57,58)$.

\section{Immunohistochemistry versus MALDI TOF}

At present, the most commonly used method for differentiation of breast cancer subtypes is immunohistochemical classification, based on the level of expression of ERs and progesterone receptors $(41,42)$. This method provides relatively accurate results (false negativity, 15.1\%), however, it can be time-consuming when analysis of a large number of samples is necessary, requiring sample staining, incubation, application of antibodies and visualization. By contrast, MALDI TOF MS may be useful for the analysis of large amounts of tissue samples. The greatest disadvantage of MALDI MS is the acquisition costs, however, this is balanced by reduced operating costs, reliability, robustness and efficiency. Additionally, ER isolation must be performed using two-dimensional gel electrophoresis (47) or a chromatographic system, in which several issues limit the isolation and proteomic analysis of ER complexes. The greatest of these is the low amount of endogenous ERs complexed with EREs, increasing the requirement for sensitivity of analytical methods used for isolation, and therefore it is necessary to find compromise between protein isolation efficiency and accuracy of the method utilized for its detection (50). However, MALDI may be useful for other applications, for example the monitoring of cancer gene expression $(53,59)$.

\section{Conclusions}

ER proteins are important for diagnostics and classification of breast tumors subtypes. In particular, the need for identification of the cancer subtype is vital for selection of the appropriate treatment, and to predict the chemoresistance which is commonly noted in $\mathrm{ER}^{+}$tumors. At present, immunohistochemistry provides good results, however, this technique is laborious. Large diagnostic potential has been attributed to MALDI TOF MS but, due to the relatively recent development and high cost, the use of this application in clinical practice remains uncommon.

\section{Acknowledgements}

This study was supported by grants from the Internal Grant Agency of the University of Veterinary and Pharmaceutical Sciences Brno (project 4/2013/FVHE) and MSMT (no. 6215712402).

\section{References}

1. Jemal A, Bray F, Center MM, Ferlay J, Ward E and Forman D: Global cancer statistics. CA Cancer J Clin 61: 69-90, 2011.

2. Siegel R, Naishadham D and Jemal A: Cancer statistics, 2013. CA Cancer J Clin 63: 11-30, 2013

3. Patani N, Martin LA and Dowsett M: Biomarkers for the clinical management of breast cancer: international perspective. Int J Cancer 133: 1-13, 2013.

4. Carey LA, Perou CM, Livasy CA, et al: Race, breast cancer subtypes, and survival in the Carolina Breast Cancer Study. JAMA 295: 2492-2502, 2006.

5. Yang XR, Chang-Claude J, Goode EL, et al: Associations of breast cancer risk factors with tumor subtypes: a pooled analysis from the Breast Cancer Association Consortium studies. J Natl Cancer Inst 103: 250-263, 2011.

6. Muss HB: Coming of age: breast cancer in seniors. Oncologist 16 (Suppl 1): S79-S87, 2011.

7. Ma H, Wang Y, Sullivan-Halley J, et al: Use of four biomarkers to evaluate the risk of breast cancer subtypes in the women's contraceptive and reproductive experiences study. Cancer Res 70: 575-587, 2010.

8. Shubbar E, Helou K, Kovács A, et al: High levels of $\gamma$-glutamyl hydrolase $(\mathrm{GGH})$ are associated with poor prognosis and unfavorable clinical outcomes in invasive breast cancer. BMC Cancer 13: 47, 2013.

9. Tian W, Chen J, He H and Deng Y: MicroRNAs and drug resistance of breast cancer: basic evidence and clinical applications. Clin Transl Oncol 15: 335-342, 2013.

10. Ombra MN, Di Santi A, Abbondanza C, Migliaccio A, Avvedimento EV and Perillo B: Retinoic acid impairs estrogen signaling in breast cancer cells by interfering with activation of LSD1 via PKA. Biochim Biophys Acta 1829: 480-486, 2013.

11. Fasching PA, Heusinger K, Haeberle L, et al: Ki67, chemotherapy response, and prognosis in breast cancer patients receiving neoadjuvant treatment. BMC Cancer 11: 486, 2011.

12. Sharan S, Nikhil K and Roy P: Effects of low dose treatment of tributyltin on the regulation of estrogen receptor functions in MCF-7 cells. Toxicol Appl Pharmacol 269: 176-186, 2013.

13. Yan Y, Liu H, Wen H, et al: The novel estrogen receptor GPER regulates the migration and invasion of ovarian cancer cells. Mol Cell Biochem 378: 1-7, 2013.

14. Oh Y and Chung KC: Zinc finger protein 131 inhibits estrogen signaling by suppressing estrogen receptor $\alpha$ homo-dimerization. Biochem Biophys Res Commun 430: 400-405, 2013 
15. Komm BS and Mirkin S: Evolution of the tissue selective estrogen complex (TSEC). J Cell Physiol 228: 1423-1427, 2013.

16. Cheng Q, Chang JT, Geradts J, et al: Amplification and high-level expression of heat shock protein 90 marks aggressive phenotypes of human epidermal growth factor receptor 2 negative breast cancer. Breast Cancer Res 14: R62, 2012.

17. Coughlan N, Thillainadesan G, Andrews J, Isovic M and Torchia J: $\beta$-Estradiol-dependent activation of the JAK/STAT pathway requires p/CIP and CARM1. Biochim Biophys Acta-Mol Cell Res 1833: 1463-1475, 2013.

18. Sengupta S, Obiorah I, Maximov PY, Curpan R and Jordan VC: Molecular mechanism of action of bisphenol and bisphenol A mediated by oestrogen receptor alpha in growth and apoptosis of breast cancer cells. Br J Pharmacol 169: 167-178, 2013.

19. Levin ER: Integration of the extranuclear and nuclear actions of estrogen. Mol Endocrinol 19: 1951-1959, 2005.

20. Pirman DA, Efuet E, Ding XP, et al: Changes in cancer cell metabolism revealed by direct sample analysis with MALDI mass spectrometry. PLoS One 8: e61379, 2013.

21. Cornett DS, Reyzer ML, Chaurand P and Caprioli RM: MALDI imaging mass spectrometry: molecular snapshots of biochemical systems. Nat Methods 4: 828-833, 2007.

22. Wang HS, Wu HM, Cheng BH, et al: Functional analyses of endometriosis-related polymorphisms in the estrogen synthesis and metabolism-related genes. PLoS One 7: e47374, 2012.

23. Srinivasan S, Nwachukwu JC, Parent AA, et al: Ligand-binding dynamics rewire cellular signaling via estrogen receptor- $\alpha$. Nat Chem Biol 9: 326-332, 2013.

24. Aust S, Horak P, Pils D, et al: The prognostic value of estrogen receptor beta and proline-, glutamic acid- and leucine-rich protein 1 (PELP1) expression in ovarian cancer. BMC Cancer 13: 115, 2013.

25. Borjesson AE, Farman HH, Engdahl C, et al: The role of activation functions 1 and 2 of estrogen receptor- $\alpha$ for the effects of estradiol and selective estrogen receptor modulators in male mice. J Bone Miner Res 28: 1117-1126, 2013.

26. Zeng H, Wu JC, Bedford MT, et al: A TR-FRET-based functional assay for screening activators of CARM1. Chembiochem 14 827-835, 2013

27. Meric-Bernstam F, Gutierrez-Barrera AM, Litton J, et al: Genotype in BRCA-associated breast cancers. Breast J 19: 87-91, 2013.

28. Jiang H, Teng R, Wang Q, et al: Transcriptional analysis of estrogen receptor alpha variant mRNAs in colorectal cancers and their matched normal colorectal tissues. J Steroid Biochem Mol Biol 112: 20-24, 2008

29. Wang J, Li J, Fang R, Xie S, Wang L and Xu C: Expression of ERa36 in gastric cancer samples and their matched normal tissues. Oncol Lett 3: 172-175, 2012.

30. Tu BB, Lin SL, Yan LY, Wang ZY, Sun QY and Qiao J: ER- $\alpha 36$, a novel variant of estrogen receptor $\alpha$, is involved in EGFR-related carcinogenesis in endometrial cancer. Am J Obstet Gynecol 205: 227.e1-e6, 2011.

31. Kammerer M, Gutzwiller S, Stauffer D, Delhon I, Seltenmeyer Y and Fournier B: Estrogen receptor $\alpha(\mathrm{ER} \alpha)$ and estrogen related receptor $\alpha(E R R \alpha)$ are both transcriptional regulators of the Runx2-I isoform. Mol Cell Endocrinol 369: 150-160, 2013.

32. Gamucci T, Vaccaro A, Ciancola F, et al: Recurrence risk in small, node-negative, early breast cancer: a multicenter retrospective analysis. J Cancer Res Clin Oncol 139: 853-860, 2013.

33. Althuis MD, Fergenbaum JH, Garcia-Closas M, Brinton LA, Madigan MP and Sherman ME: Etiology of hormone receptor-defined breast cancer: a systematic review of the literature. Cancer Epidemiol Biomarkers Prev 13: 1558-1568, 2004.

34. Thrane S, Lykkesfeldt AE, Larsen MS, Sorensen BS and Yde CW: Estrogen receptor $\alpha$ is the major driving factor for growth in tamoxifen-resistant breast cancer and supported by HER/ERK signaling. Breast Cancer Res Treat 139: 71-80, 2013.

35. Foulkes WD, Smith IE and Reis-Filho JS: Triple-negative breast cancer. N Engl J Med 363: 1938-1948, 2010.

36. Ramirez-Ardila DE, Helmijr JC, Look MP, et al: Hotspot mutations in PIK3CA associate with first-line treatment outcome for aromatase inhibitors but not for tamoxifen. Breast Cancer Res Treat 139: 39-49, 2013.

37. Hiscox S, Davies EL and Barrett-Lee P: Aromatase inhibitors in breast cancer. Maturitas 63: 275-279, 2009.

38. Hodgkinson VC, Agarwal V, El Fadl D, et al: Pilot and feasibility study: comparative proteomic analysis by 2-DE MALDI TOF/TOF MS reveals 14-3-3 proteins as putative biomarkers of response to neoadjuvant chemotherapy in ER-positive breast cancer. J Proteomics 75: 2745-2752, 2012.
39. Kim SI, Sohn J, Koo JS, Park SH, Park HS and Park BW: Molecular subtypes and tumor response to neoadjuvant chemotherapy in patients with locally advanced breast cancer. Oncology 79: 324-330, 2010.

40. Haddock CL, Holtz B, Senzer N and Nemunaitis J: Applications of HPLC-MALDI-TOF MS/MS phosphoproteomic analysis in oncological clinical diagnostics. Curr Proteomics 8: 153-167, 2011.

41. Tangjitgamol S, Tanvanich S, Srijaipracharoen S and Manusirivithaya S: Expression of estrogen receptor, progesterone receptor, and Her-2/neu in primary and extra-corporeal endometrial cancer. Histol Histopathol 28: 787-794, 2013.

42. Alkner S, Bendahl PO, Grabau D, et al: The role of AIB1 and PAX2 in primary breast cancer: validation of AIB1 as a negative prognostic factor. Ann Oncol 24: 1244-1252, 2013.

43. Seferina SC, Nap M, van den Berkmortel F, Wals J, Voogd AC and Tjan-Heijnen VC: Reliability of receptor assessment on core needle biopsy in breast cancer patients. Tumour Biol 34: 987-994, 2013.

44. Wik E, Ræder MB, Krakstad C, et al: Lack of estrogen receptor- $\alpha$ is associated with epithelial-mesenchymal transition and PI3K alterations in endometrial carcinoma. Clin Cancer Res 19: 1094-1105, 2013

45. Kinsella MD, Birdsong GG, Siddiqui MT, Cohen C and Hanley KZ: Immunohistochemical detection of estrogen receptor, progesterone receptor and human epidermal growth factor receptor 2 in formalin-fixed breast carcinoma cell block preparations: correlation of results to corresponding tissue block (needle core and excision) samples. Diagn Cytopathol 41: 192-198, 2013.

46. Sang QX, Man YG, Sung YM, et al: Non-receptor tyrosine kinase 2 reaches its lowest expression levels in human breast cancer during regional nodal metastasis. Clin Exp Metastasis 29: 143-153, 2012.

47. Jin Y, Zhang X, Lu D, et al: Histopathological and proteomic analysis of hepatic tissue from adult male zebrafish exposed to 17 $\beta$-estradiol. Environ Toxicol Pharmacol 29: 91-95, 2010.

48. Pietrowska M, Marczak L, Polanska J, et al: Mass spectrometry-based serum proteome pattern analysis in molecular diagnostics of early stage breast cancer. J Transl Med 7: 60, 2009.

49. Bouchal P, Dvorakova M, Scherl A, Garbis SD, Nenutil R and Vojtesek B: Intact protein profiling in breast cancer biomarker discovery: protein identification issue and the solutions based on 3D protein separation, bottom-up and top-down mass spectrometry. Proteomics 13: 1053-1058, 2013.

50. Nalvarte I, Schwend T and Gustafsson JA: Proteomics analysis of the estrogen receptor alpha receptosome. Mol Cell Proteomics 9: 1411-1422, 2010.

51. Atsriku C, Benz CC, Scott GK, Gibson BW and Baldwin MA: Quantification of cysteine oxidation in human estrogen receptor by mass spectrometry. Anal Chem 79: 3083-3090, 2007.

52. CornettDS, Mobley JA, Dias EC, et al: A novel histology-directed strategy for MALDI-MS tissue profiling that improves throughput and cellular specificity in human breast cancer. Mol Cell Proteomics 5: 1975-1983, 2006.

53. Kabbage M, Trimeche M, Bergaoui S, et al: Calreticulin expression in infiltrating ductal breast carcinomas: relationships with disease progression and humoral immune responses. Tumour Biol 34: 1177-1188, 2013.

54. Castilla MÁ, Diaz-Martin J, Sarrió D, et al: MicroRNA-200 family modulation in distinct breast cancer phenotypes. PLoS One 7: e47709, 2012

55. Paramanik V and Thakur MK: Estrogen receptor $\beta$ and its domains interact with casein kinase 2 , phosphokinase $C$, and $\mathrm{N}$-myristoylation sites of mitochondrial and nuclear proteins in mouse brain. J Biol Chem 287: 22305-22316, 2012.

56. Bovet C, Plet B, Ruff M, et al: Towards high-throughput identification of endocrine disrupting compounds with mass spectrometry. Toxicol In Vitro 23: 704-709, 2009.

57. Collodoro M, Lemaire P, Eppe G, et al: Identification and quantification of concentration-dependent biomarkers in MCF-7/BOS cells exposed to $17 \beta$-estradiol by 2 -D DIGE and label-free proteomics. J Proteomics 75: 4555-4569, 2012.

58. Lai TC, Chou HC, Chen YW, et al: Secretomic and proteomic analysis of potential breast cancer markers by two-dimensional differential gel electrophoresis. J Proteome Res 9: 1302-1322, 2010.

59. Obazee O, Justenhoven C, Winter S, et al: Confirmation of the reduction of hormone replacement therapy-related breast cancer risk for carriers of the HSD17B1_937_G variant. Breast Cancer Res Treat 138: 543-548, 2013. 